\title{
A One-Dimensional Model of Steady, Compressible Channel Flow With Mass, Momentum, and Energy Addition
}

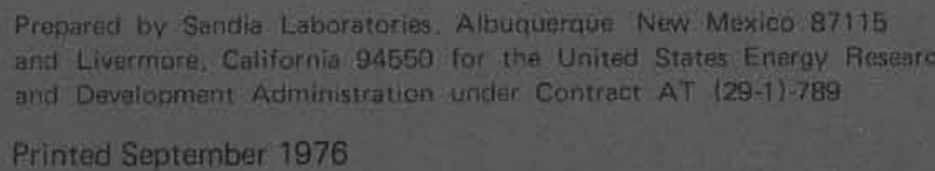

When printing a copy of any digitized SAND Report, you are required to update the markings to current standards. 
Issued by Sandia Laboratories, operated for the United States Energy Research and Development Administration by Sandia Corporation.

\section{NOTICE}

This report was prepared as an account of work sponsored by the United States Government. Neither the United States nor the United States Energy Research and Development Administration, nor any of their employees, nor any of their contractors, subcontractors, or their employees, makes any warranty, express or implied, or assumes any legal liability or responsibility for the accuracy, completeness or usefulness of any information, apparatus, product or process disclosed, or represents that its use would not infringe privately owned rights. 
SAND76-8244

Unlimited Distribution

September 1976

A ONE-DIMENSIONAL MODEL OF STEADY, COMPRESSIBLE

CHANNEL FLOW WITH MASS, MOMENTUM, AND ENERGY ADDITION

S. C. Johnston

Combustion Applications Division 8116

ABSTRACT

A one-dimensional mode1 of steady, compressible channel flow with mass, momentum and energy addition is discussed. An exact solution to the governing equations was found and from it a similarity parameter relating dimensionless mass, momentum and energy addition identified. This similarity parameter is used to make two flows having different dimensionless mass, momentum and energy additions equivalent. Application of the similarity parameter to the LASL Intense Neutron Source experiment and the Sandia simulation of that experiment results in an expression relating the dimensionless mass addition of combustible gas required in the Sandia experiment to dimensionless energy addition in the LASL experiment. Results of the analysis indicate that the Sandia experiment can realistically simulate the energy addition in the LASL Intense Neutron Source experiment. 
NOMENCLATURE

English Symbols
A Area
a Dimensionless mass addition
b Dimensionless momentum addition
c Dimensionless energy addition
$\mathrm{C}_{\mathrm{P}} \quad$ Specific heat at constant pressure
$\mathrm{C}_{\mathrm{V}} \quad$ Specific heat at constant volume
h Step height, specific enthalpy
h' Height of secondary flow nozzle exit
H Upstream channel height
L Channel width
M Mach number
$\hat{\mathrm{M}}_{\mathbf{i}} \quad$ Molecular weight of species $i$
$\dot{\mathrm{m}} \quad$ Mass flow rate
P Static pressure
$\mathrm{P}_{0} \quad$ Stagnation pressure
Q Heat addition by a11 other means besides combustion, per unit mass
q Heat addition by combustion, per unit mass of combustible mixture
$\hat{\mathrm{R}} \quad$ Universal gas constant
T Static temperature
$\mathrm{T}_{0} \quad$ Stagnation temperature
V Velocity
$\mathrm{Y}_{i} \quad$ Mass fraction of species $i$ 
Greek Symbols

$\begin{array}{ll}\alpha & \text { Dimensionless step height, } h / H \\ \alpha^{\prime} & \text { Dimensionless secondary flow exit height, } h^{\prime} / \mathrm{H} \\ \gamma & \text { Specific heat ratio } \\ \lambda & \text { Similarity parameter } \\ \rho & \text { Gas density }\end{array}$

Subscripts

1

Station 1

2

Station 2

$\mathrm{g}$

Station $g$, of the secondary flow

i inert

$r \quad$ reacting

$\max \quad \operatorname{maximum}$ conditions 


\section{Introduction}

The Division of Magnetic Fusion Energy (DMFE) of the Energy Research and Development Administration is vigorously pursuing the development of fusion power reactors to be used in the year 2000 and beyond. One important aspect of a $\mathrm{D}-\mathrm{T}$ fusion reactor is the production of a large flux of $14 \mathrm{-MeV}$ neutrons which can potentially cause both bulk (e.g., atom displacement, generation of large quantities of helium and hydrogen gas) and surface (e.g., neutron sputtering, radiation blistering) damage to the materials containing the $\mathrm{D}-\mathrm{T}$ reaction. These fusion produced neutrons are of a much higher energy than those produced in fission reactors and their nuclear reactions differ. Thus, materials problems heretofore unencountered must be anticipated and their extent determined prior to full scale fusion reactor operation.

Several research laboratories have proposed building an intense neutron source to accurately simulate the fusion reactor environment to test and develop materials for those reactors [1]. These proposals include rotatingsolid target, liquid and solid target, mixed (deuteron and triton beam drive-in target and supersonic-gas jet target neutron sources. The supersonic-gas jet target has been proposed by the Los Alamos Scientific Laboratory (LASL). In this design, which is called the Intense Neutron Source (INS), a co-axial supersonic flow of deuterium (Fig. 1) provides both the gas target for a tritium ion beam and the means of dissipating the $1 / 3$ megawatt of heat which is deposited at the target by the $270 \mathrm{KeV}$ 


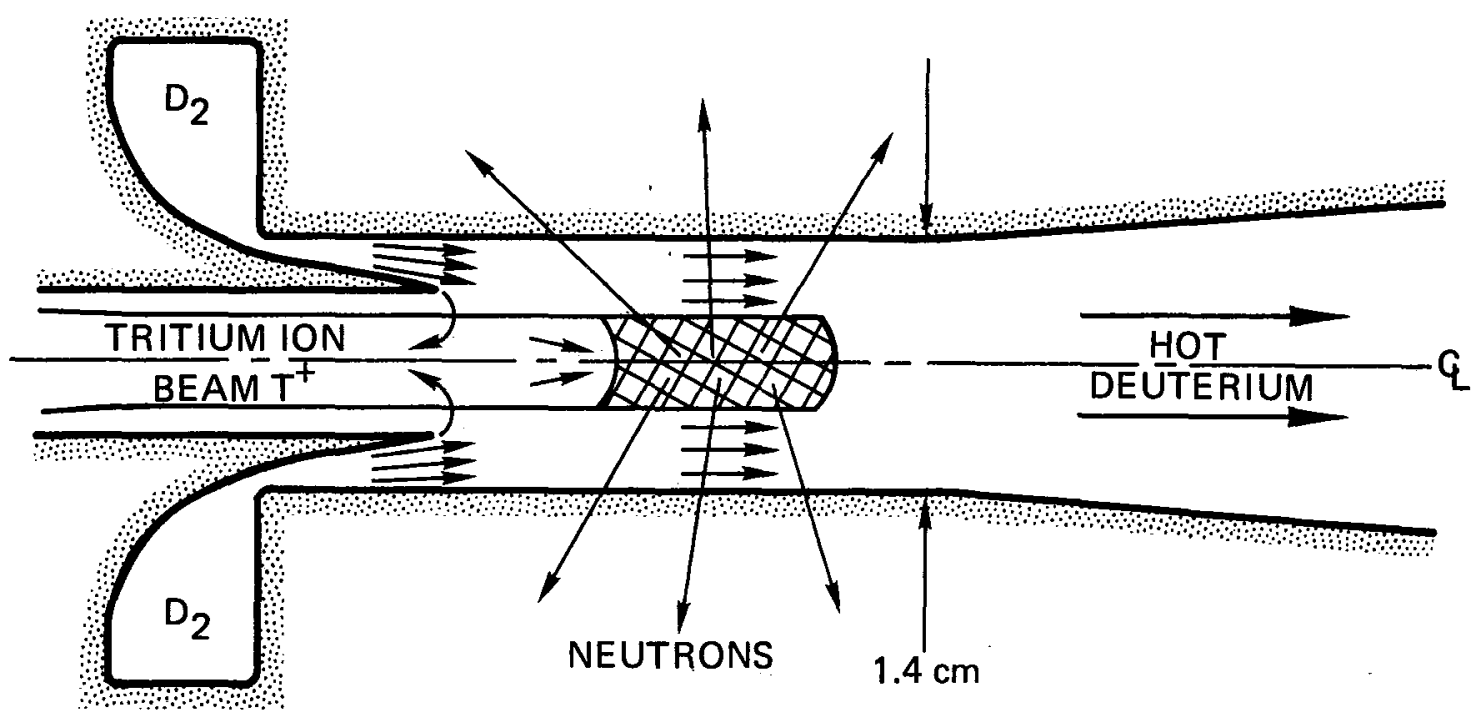

Figure 1: One Possible Configuration of the LASL Intense Neutron Source (INS) Channe1

ion beam. The resulting D-T reaction at the target (which is about $1 \mathrm{~cm}^{3}$ in volume) provides a continuous neutron flux of $10^{15}$ neutron/sec. This neutron flux irradiates the walls of the expansion nozzle, which are constructed of the material under test.

From a gasdynamic viewpoint, several important phenomena must be considered in the INS nozzle design. These include 1) the possibility of a significant flow of deuterium back up the tritium ion beam port, which for purposes of ion beam transport must be kept at a pressure of about 1 torr and 2) choking of the supersonic deuterium flow. The deuterium stream begins its expansion to a supersonic Mach number at a stagnation pressure of about 6000 psi, ending up with a static pressure of several psia at the target. This pressure differential provides the driving force for back-flow up the ion beam channel. Back-flow is highly undesirable because it increases the 
vacuum pumping requirements in the channel and can potentially create premature $\mathrm{D}-\mathrm{T}$ reaction in the channel.

Energy deposition levels of $1 / 3$ megawatt in the supersonic flow can by no means be considered a small perturbation to the flow. Cline [2] has numerically simulated the INS flow to determine back-flow rates and establish choking conditions for the deuterium flow. The deuterium flow can choke as the energy deposition level is increased thus causing increased static pressures at the target which in turn lead to increased back-flow rates and an increasing inability of the deuterium flow to dissipate the heat deposited at the target.

Cline's [2] calculations have indicated that with large energy deposition levels (two times the incoming deuterium total kinetic energy flow rate) about $7 \%(\sim 5.6 \mathrm{~g} / \mathrm{s})$ of the main deuterium flow travels back up the ion beam port. The difficulty in experimental verification of Cline's results lies in proper duplication of the energy deposition, since the full INS facility will not be available for several years. A proton (hydrogen ion) beam experiment is being built at LASL to study some of these effects, but it is about a year away from being completely operational. In a scaleddown version of the free-jet deuterium target proposed in [3], Robinson, et a1. [4] heated free-jet gas targets using a KeV energy electron beam. Heating ratios (defined as the ratio of beam energy to gas thermal energy) of $0.25,0.50$, and 0.65 were achieved for helium, argon and nitrogen, respectively.

Sandia Laboratories, Livermore, has been funded by the DMFE to simulate the LASL experiment by chemically depositing energy in a supersonic channel flow using a $\mathrm{H}_{2}-\mathrm{O}_{2}$ flame, Figure 2. In this experiment, the combustible gases are introduced into the main flow via an opposed-jet. The momentum of this 
jet is dissipated by the main flow some distance downstream of the combustible gas nozzle exit. This causes the opposed-jet to turn back on itself and flow with the main stream. Ignition of the combustible gases provides the required energy deposition.

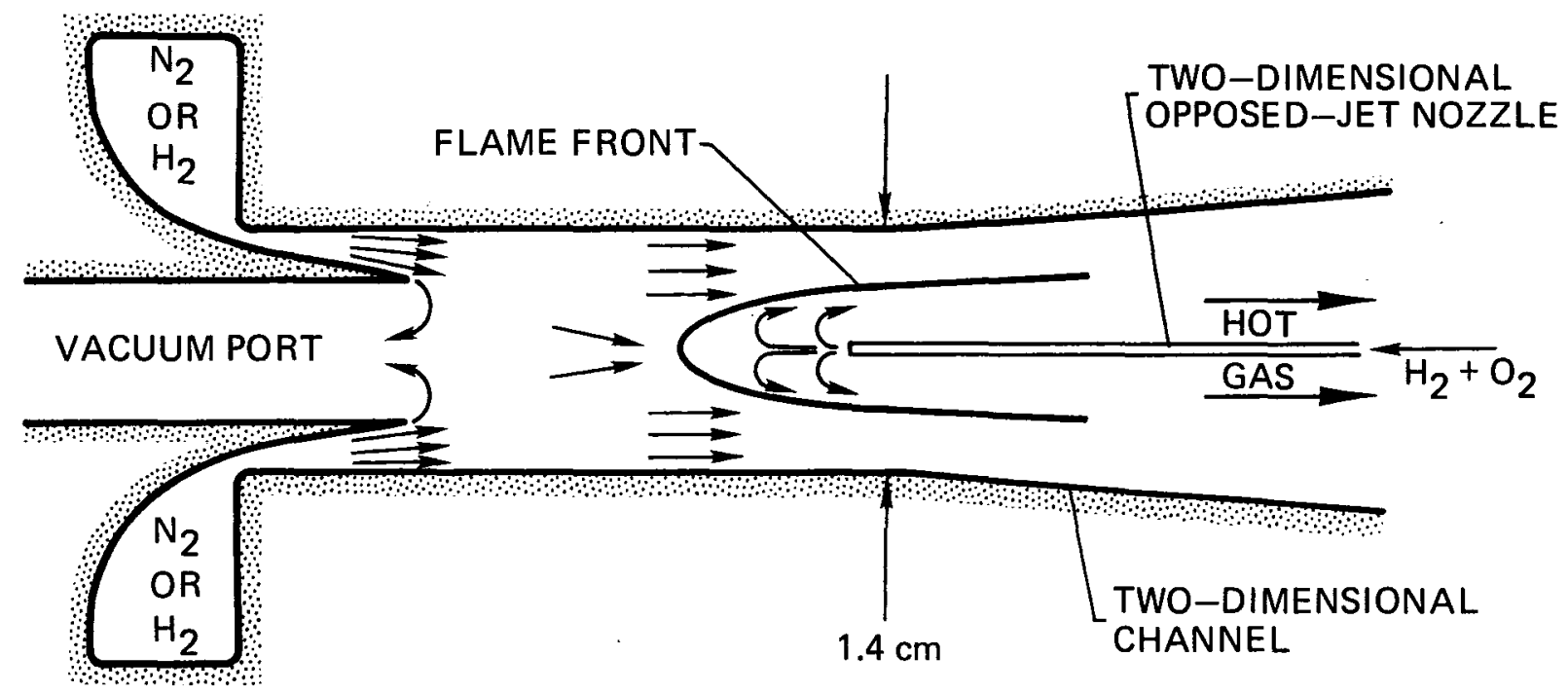

Figure 2: Two-Dimensional Sandia Simulation of Energy Deposition in INS

In contrast to the INS nozzle, which is axisymmetric, the Sandia experiment is two-dimensional, having quartz windows for optical access of the entire flow. Such things as visual determination of flow patterns and shock wave structure, optical temperature, density and velocity measurement are possible with this design. The Sandia experiment has a simulated ion beam channe1 which can be evacuated to INS vacuum pressure levels. This allows for the measurement of back-flow rates into this channel as a function of energy deposition leve1 (with the $\mathrm{H}_{2}-\mathrm{O}_{2}$ flame, full scale energy deposition 
can be attained). The experiment is about $70 \%$ operational at this writing. Cold-flow schlieren cinematography results as we11 as wall pressure measurements have been obtained.

The concept of the opposed-jet flame is not new - it was studied extensively [5 thru 11] in the $1950^{\prime}$ 's for application to flame stabilization in supersonic combustion. In addition, the supersonic flow past the ion beam port is somewhat similar to supersonic flow over a wedge having base suction or wake combustion. These topics have also received considerable attention [13 thru 16]. Schaffer [5] has obtained data which show that the shape of the flame (and hence the shape of the energy deposition region) can be modified by adjusting the flame nozzle exit height and combustible gas stagnation pressure. This will allow some tailoring of the energy deposition region so that the Sandia experiment can be made to more accurately simulate the energy deposition region in the INS.

In the INS, the mass flow rate of deuterium is $80 \mathrm{~g} / \mathrm{s}$ and the mass flow rate of the tritium ion beam is $4 \times 10^{-5} \mathrm{~g} / \mathrm{s}$. This means that negligible mass and momentum are added to the deuterium flow. In the Sandia simulation experiment, however, mass and energy are added to and momentum is extracted from the main flow. A serious question arises as to how good a simulation the Sandia experiment is of the INS if the perturbation of the main supersonic flow is so radically different between the two. The purpose of this report is to analytically address this topic and to determine the criteria which must be applied to realistically simulate the LASL INS experiment. In the discussion that follows, a one-dimensional flow model with a step-change in area is developed. It is obvious that the energy deposition region in the Sandia simulation experiment is two-dimensional. However, the purpose of the one-dimensional analysis is to provide the information 
necessary to guide the experiment and to interpret results, and in this sense, is completely adequate. It is possible that differences in measured pressures and other flow parameters could differ between two experiments identical in every detail save that one is axisymmetric and the other is two-dimensional. This occurs in the external flow over a cone and a wedge. However, without either a good numerical simulation or experiments designed specifically to evaluate these phenomena, it is difficult to say if differences in a measured quantity such as pressure are large or small between an axisymmetric and a two-dimensional experiment. For the analysis presented here, this is a mute point, however, since these differences are not capable of being represented by a one-dimensional model. 
II. Analysis and Discussion of Results

If viscous effects are neglected, the flow geometry of Figure 2 can be approximated by the half-span mode1 shown in Figure 3, where the center streamline has been replaced by a solid boundary. The main flow is assumed to expand supersonically from the upstream nozzle throat to a uniform (onedimensiona1) supersonic flow at station(1) of the control surface. Schlieren photographs [19] indicate that the main channel flow passes through an oblique shock wave before reaching station(1), but the approximation is made here that the total pressure loss through the oblique shock wave is negligible. Back-flow losses to mass flow rate are not considered in the model. Although there is some degree of natural unsteadiness to the opposed-jet flowfield, these effects are small [5] and can be neglected in this analysis.

At station (g), a secondary combustible stream is injected at sonic velocity into the control surface. This secondary flow is assumed to be one-dimensional at station (g), as is the combined flow at station (2). Inside the control surface, the flow is two-dimensional. The governing one-dimensional equations for the half-span model of Figure 3 are derived in Appendix $\mathrm{A}$ and are

$$
\begin{array}{rr}
\rho_{2} \mathrm{~V}_{2}=\rho_{1} \mathrm{~V}_{1} \frac{(1+\mathrm{a})}{(1-\alpha)} & \text { Continuity } \\
\mathrm{P}_{2}+\rho_{2} \mathrm{~V}_{2}^{2}=\left(\mathrm{P}_{1}+\rho_{1} \mathrm{~V}_{1}^{2}\right) \frac{(1+\mathrm{b})}{(1-\alpha)} & \text { Momentum }
\end{array}
$$




$$
\begin{array}{cc}
\frac{\gamma_{2}}{\gamma_{2}-1} \frac{P_{2}}{\rho_{2}}+\frac{V_{2}^{2}}{2}=\left[\frac{\gamma_{1}}{\gamma_{1}-1} \frac{P_{1}}{\rho_{1}}+\frac{V_{1}^{2}}{2}\right] \frac{(1+c)}{(1+a)} & \text { Energy } \\
P=\rho \hat{R} T \sum_{i=1}^{N}\left(Y_{i} / \hat{M}_{i}\right) & \text { State }
\end{array}
$$

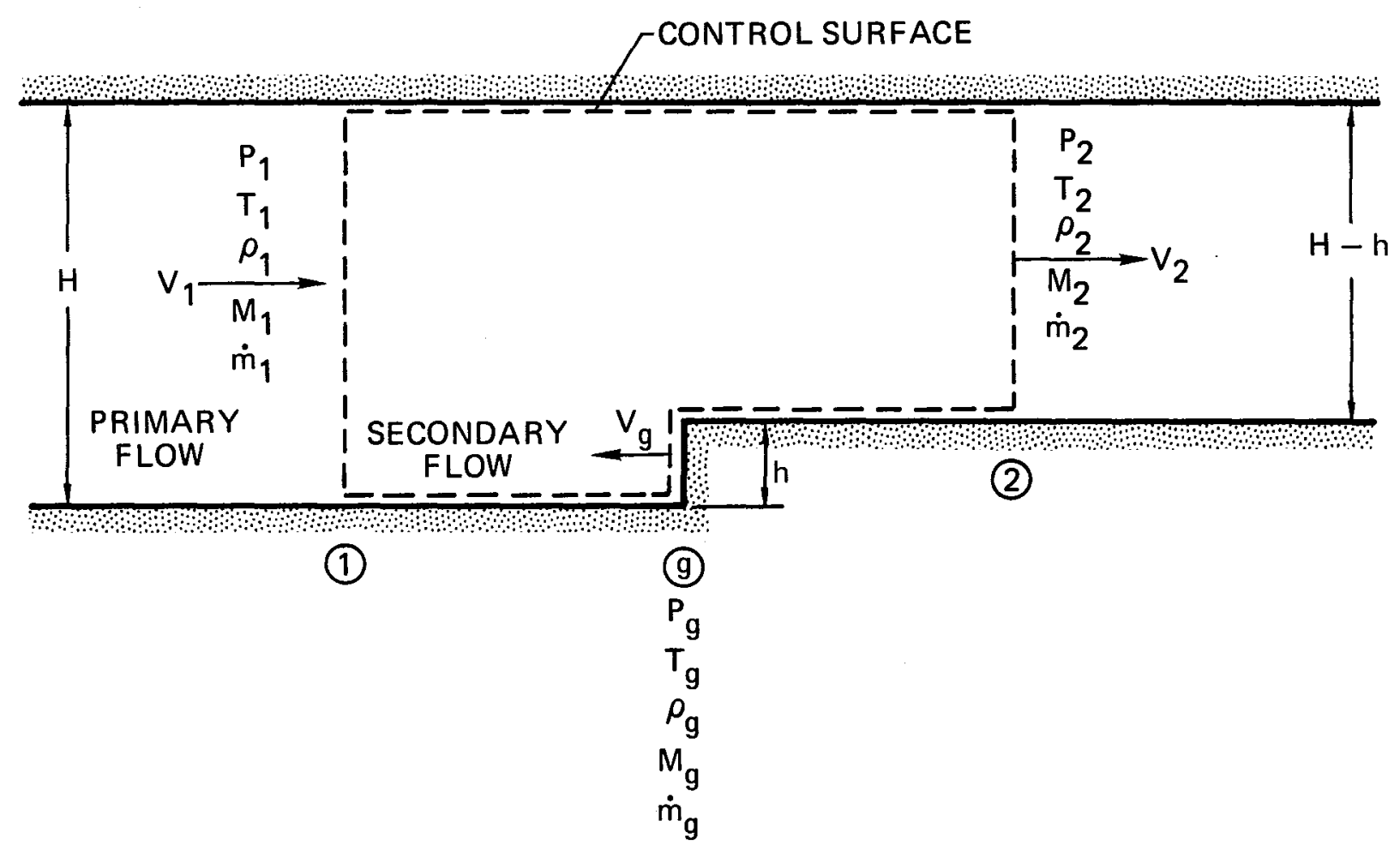

Figure 3: One-Dimensional Planar Mode1 Used in the Analysis

where $\rho, \mathrm{P}$ and $\mathrm{V}$ are gas density, pressure and velocity, respectively. $\alpha$ is the dimensionless step height, $Y_{i}$ is the mass fraction and $\hat{M}_{i}$ is the molecular weight of species $i . \gamma$ is the ratio of specific heats, which are assumed to vary only because of species changes between stations (1) and (2) and not because of temperature changes between these stations.

There is an exact solution to the above set of equations, which, after some algebra, can be shown to be 


$$
\begin{aligned}
& \frac{\rho_{1}}{\rho_{2}} \frac{(1+a)^{2}}{(1-\alpha)(1+b)}=\frac{V_{2}}{V_{1}} \frac{(1+a)}{(1+b)}= \\
& \frac{1}{\gamma_{2}^{+1}}\left[\frac{\gamma_{2}}{\gamma_{1}}\left(\gamma_{1}+\frac{1}{\mathrm{M}_{1}^{2}}\right) \pm\left\{\left[\frac{\gamma_{2}}{\gamma_{1}}\left(\gamma_{1}+\frac{1}{\mathrm{M}_{1}^{2}}\right)\right]^{2}-2 \frac{\left(\gamma_{2}-1\right)}{\left(\gamma_{1}-1\right)}\left(\gamma_{2}+1\right)\left(\frac{1}{\mathrm{M}_{1}^{2}}+\frac{\gamma_{1}-1}{2}\right)\right.\right. \\
& \left.\left.\frac{(1+c)(1+a)}{(1+b)^{2}}\right\}^{1 / 2}\right]=F\left(\gamma_{1}, \gamma_{2}, M_{1}^{2}, \lambda\right) \\
& \frac{\mathrm{P}_{2}}{\mathrm{P}_{1}} \frac{(1-a)}{(1+b)}=\frac{M_{1}^{2}}{\gamma_{2}^{+1}}\left[\left(\gamma_{1}+\frac{1}{M_{1}^{2}}\right) \mp \gamma_{1}\{\%\}^{1 / 2}\right]=G\left(\gamma_{1}, \gamma_{2}, M_{1}^{2}, \lambda\right) \\
& M_{2}^{2}=\frac{\gamma_{1}}{\gamma_{2}} \frac{\left[\frac{\gamma_{2}}{\gamma_{1}}\left(\gamma_{1}+\frac{1}{M_{1}^{2}}\right) \pm\{\%\}^{1 / 2}\right]}{\left[\left(\gamma_{1}+\frac{1}{M_{1}^{2}}\right)^{\mp} \gamma_{1}\{\%\}^{1 / 2}\right]}=H\left(\gamma_{1}, \gamma_{2}, M_{1}^{2}, \lambda\right)
\end{aligned}
$$

where

$$
\lambda=\frac{(1+c)(1+a)}{(1+b)^{2}} \text { and }\{\%\}^{1 / 2} \text { denotes the quantity in brackets in }(5) .
$$

$\mathrm{a}, \mathrm{b}$ and $\mathrm{c}$ are dimensionless mass, momentum and energy additions, respectively. If $\gamma$ variation is neglected, the above three equations reduce to

$$
\frac{\rho_{1}}{\rho_{2}} \frac{(1+a)^{2}}{(1-\alpha)(1+b)}=\tilde{\rho}=\frac{V_{2}}{V_{1}} \frac{(1+a)}{(1+b)}=\tilde{V}=F^{\prime}\left(\gamma, M_{1}^{2}, \lambda\right)
$$




$$
\begin{gathered}
\frac{\mathrm{P}_{2}}{\mathrm{P}_{1}} \frac{(1-\alpha)}{(1+b)}=\tilde{\mathrm{P}}=\mathrm{G}^{\prime}\left(\gamma, \mathrm{M}_{1}^{2}, \lambda\right) \\
\mathrm{M}_{2}^{2}=\mathrm{H}^{\prime}\left(\gamma, \mathrm{M}_{1}^{2}, \lambda\right)
\end{gathered}
$$

where $\tilde{\rho}, \tilde{\mathrm{V}}$ and $\tilde{\mathrm{P}}$ are reduced density, velocity and pressure, respectively.

Consider two flows having the same value of $\gamma$ and initial Mach number, $M_{1}$. Equations (8) thru (10) indicate that these two flows will have identical reduced flow quantities provided that the two flows have the same value of $\lambda$. In this sense, $\lambda$ can be thought of as a similarity parameter (see [17]) between the two flows and shows how two flows having different dimensionless mass, momentum and energy addition can be made equivalent, in terms of the reduced flow quantities. This means that in a general sense, there is an equivalency between mass, momentum and energy addition to a compressible channel flow. It should be noted that the form of $\lambda$ derived here differs from that obtained by Zierep [17] because Zierep does not consider energy addition by combustion in the secondary stream. Inclusion of secondary stream combustion results in the $(1+a)$ term in the energy equation (3).

Equations (8) thru (10) indicate that multiple solutions are possible, since two signs appear in front of the radical. This sign ambiguity can be cleared up by considering first the case where $\lambda=1$.

$$
\text { Case a) } \lambda=1 \quad(a=b=c=0)
$$


In this case, the above solution reduces to the classical solution of one-dimensional compressible flow in a constant area channel. Equation (10) can be shown to reduce to

$$
M_{2}^{2}=\frac{\left[1+\gamma M_{1}^{2} \pm\left(M_{1}^{2}-1\right)\right]}{\left[1+\gamma M_{1}^{2} \mp \gamma\left(M_{1}^{2}-1\right)\right]}
$$

If the top sign is taken, the trivial solution of $\mathrm{M}_{2}^{2}=\mathrm{M}_{1}^{2}$ results, indicating that nothing happens to the flow. This result is valid for both supersonic and subsonic values of $\mathrm{M}_{1}$.

If the bottom sign is taken, the result is

$$
M_{2}^{2}=\frac{1+\frac{\gamma-1}{2} M_{1}^{2}}{\gamma M_{1}^{2}+\frac{(1-\gamma)}{2}}
$$

which is for the passage of the flow through a normal shock wave. For this case, $M_{1}$ must be supersonic, since if $M_{1}<1$, the above equation results in $M_{2}>1$, which implies an "expansion shock." This is, of course, impossible from entropy considerations.

In summary, the present case indicates that the upper sign is to be taken for shock-free transformations and the lower sign for transformations connected through a normal shock wave. 


\section{Case b) $\lambda \neq 1$}

In this case, the individual effects of mass, momentum and energy addition for an initially subsonic or supersonic flow are determined. If $|a|,|b|$ and $|c|$ are considered to be small with respect to unity, (8) can be expanded for the shock-free transformation (upper sign) with the result

$$
\frac{\mathrm{V}_{2}}{\mathrm{~V}_{1}}=1-\frac{(\gamma+1)}{2\left(1-\frac{1}{\mathrm{M}_{1}^{2}}\right)} \mathrm{a}+\frac{\left(\gamma+\frac{1}{\mathrm{M}_{1}^{2}}\right)}{\left(1-\frac{1}{\mathrm{M}_{1}^{2}}\right)} \mathrm{b}-\frac{\left(\frac{1}{\mathrm{M}_{1}^{2}}+\frac{\gamma-1}{2}\right)}{\left(1-\frac{1}{\mathrm{M}_{1}^{2}}\right)} \mathrm{c}+\ldots \cdot
$$

This result is similar to one obtained by Zierep [17] except for the form of the coefficient of a, which is different due to the $(1+a)$ term in the energy equation (3). When $M_{1}>1$, both mass a and energy $c$ addition tend to reduce the downstream velocity and are thus qualitatively equivalent in their effect on the flow. Momentum addition $b$ tends to increase the downstream velocity. Momentum extraction, however, acts like mass and energy addition. When $M_{1}<1$, the term $\left(1-\frac{1}{M_{1}^{2}}\right)$ becomes negative and the above effects are each reversed. If energy addition alone is considered, these results are consistent with classical Rayleigh flow in which energy addition always drives the Mach number towards unity.

When (8) is expanded for the normal shock transformation, the result is 


$$
\begin{aligned}
& \frac{\mathrm{V}_{2}}{\mathrm{~V}_{1}}=1-\frac{2}{\gamma+1}\left(1-\frac{1}{\mathrm{M}_{1}^{2}}\right)+\frac{\left(\gamma-1+\frac{2}{\mathrm{M}_{1}^{2}}\right)\left(\frac{\gamma-1}{2}+\frac{1}{\mathrm{M}_{1}^{2}}\right)}{(\gamma+1)\left(1-\frac{1}{\mathrm{M}_{1}^{2}}\right)} a \\
& -\frac{\left(\gamma+\frac{1}{M_{1}^{2}}\right)\left(\gamma-1+\frac{2}{M_{1}^{2}}\right)}{(\gamma+1)\left(1-\frac{1}{M_{1}^{2}}\right)} b+\frac{\left(\frac{\gamma-1}{2}\right)+\frac{1}{M_{1}^{2}}}{1-\frac{1}{M_{1}^{2}}} c+. . \cdot
\end{aligned}
$$

Again, this result is similar to one obtained by Zierep [17] except for the form of the coefficient of a. In contrast to the shock-free transformation discussed above, the normal shock transformation is such that for $M_{1}>1$, mass and energy addition tend to increase the downstream velocity whereas momentum addition decreases it.

The real value of the above analysis is not in being able to predict downstream quantities but rather in obtaining the similarity parameter, $\lambda$. An undetermined length of channel is required to obtain complete therma1 and velocity mixing at station (2). However, if we are only interested in making two flows similar with respect to reduced flow quantities, the actual location of station (2) does not matter since we can choose it to be the same in both flows. The reduced flow quantities can then be used to determine differences between the flow parameters in each flow.

In the analysis that follows, the two flows having different values of $a, b$ and $c$ are the simulation flow (Figure 2) and a constant channe1-area INS flow (Figure 1). The simulation and INS flows can be made similar if we require that

$$
\lambda=\lambda^{\prime}
$$


where $\lambda$ is for the INS flow and $\lambda^{\prime}$ is for the simulation flow. In the INS flow, $a=b=0, c \neq 0$. In the simulation flow, $a^{\prime} \neq 0, b^{\prime} \neq 0, c^{\prime} \neq 0$. There results

$$
1+c=\frac{\left(1+a^{\prime}\right)\left(1+c^{\prime}\right)}{\left(1+b^{\prime}\right)^{2}}
$$

For the INS flow,

$$
c=\frac{Q}{C_{\mathrm{P}} T_{0}} \quad \text { since }
$$

$a=0$ in $(\mathrm{A}-15)$

For the simulation flow,

$$
c^{\prime}=a^{\prime} \frac{q}{\mathrm{C}_{\mathrm{P}_{1}} \mathrm{~T} \mathrm{O}_{1}}
$$

if in (A-15) $Q$ is set equal to zero and the approximation is made that for the secondary flow, $\mathrm{C}_{\mathrm{Pg}} \mathrm{T}_{0 \mathrm{~g}} \ll \mathrm{q}$. By neglecting the contribution of $\mathrm{Q}$, we are saying that in the simulation flow energy addition by conduction and radiation are negligible compared to energy addition by combustion.

In Appendix A, it is shown that

$$
b^{\prime}=-a^{\prime} \tilde{G},
$$

where $\tilde{G}$ is the momentum dissipation function defined by (A-8). Equations (12) and (13) can be substituted into (11) to obtain an expression for the dimensionless mass addition of combustible gases required to make the simulation flow equivalent to the INS flow. The result is 


$$
a^{\prime}=\phi\left\{\left(1+\frac{2 c}{\phi}\left[1+\frac{q}{\mathrm{C}_{\mathrm{P}_{1}} \mathrm{~T}_{1}}+2(1+\mathrm{c}) \tilde{\mathrm{G}}\right]^{-1}\right)^{1 / 2}-1\right\}
$$

where

$$
\phi=\frac{1+q / C_{P_{1}}{ }^{T} 0_{1}+2(1+c) \tilde{G}}{2\left[q / C_{p_{1}}{ }^{T} 0_{1}-(1+c) \tilde{G}^{2}\right]}
$$

When terms small compared to $\mathrm{q} / \mathrm{C}_{\mathrm{P}_{1}} \mathrm{~T}_{0_{1}}$ are neglected and an expansion in $4 \mathrm{c} \mathrm{C}_{\mathrm{P}_{1}} \mathrm{~T}_{0_{1}} / \mathrm{q}$ is made with terms above second order omitted, the above equation takes on the approximate form

$$
\mathrm{a}^{\prime} \approx \mathrm{c} \frac{{ }_{\mathrm{P}_{1}}{ }^{\mathrm{T}}{ }_{0_{1}}}{\mathrm{q}}\left(1-\mathrm{c} \frac{\mathrm{C}_{1}{ }^{\mathrm{T}}{ }_{0_{1}}}{\mathrm{q}}\right)
$$

Note that in this approximate form the upstream Mach number $M_{1}$ does not appear.

In Appendix B, the equation corresponding to (14) and (15) are given for the case of a secondary flow carrier gas. Figure 4 shows the variation of $a^{\prime}, b^{\prime}$, and $c^{\prime}$ as a function of $c$ for both nitrogen and hydrogen (less costly than deuterium) main flow. The exact solution (14) was used to calculate $\mathrm{a}^{\prime}$ in Figure 4.

Nitrogen rather than hydrogen is used at the main flow for obvious safety reasons. From a chemical kinetics viewpoint, however, it may be that the inert nitrogen main flow will reduce the flame speed so much that flame stabilization will not be possible at high main flow approach velocities. This was found to be the case in [7] for the reverse experiment in which 


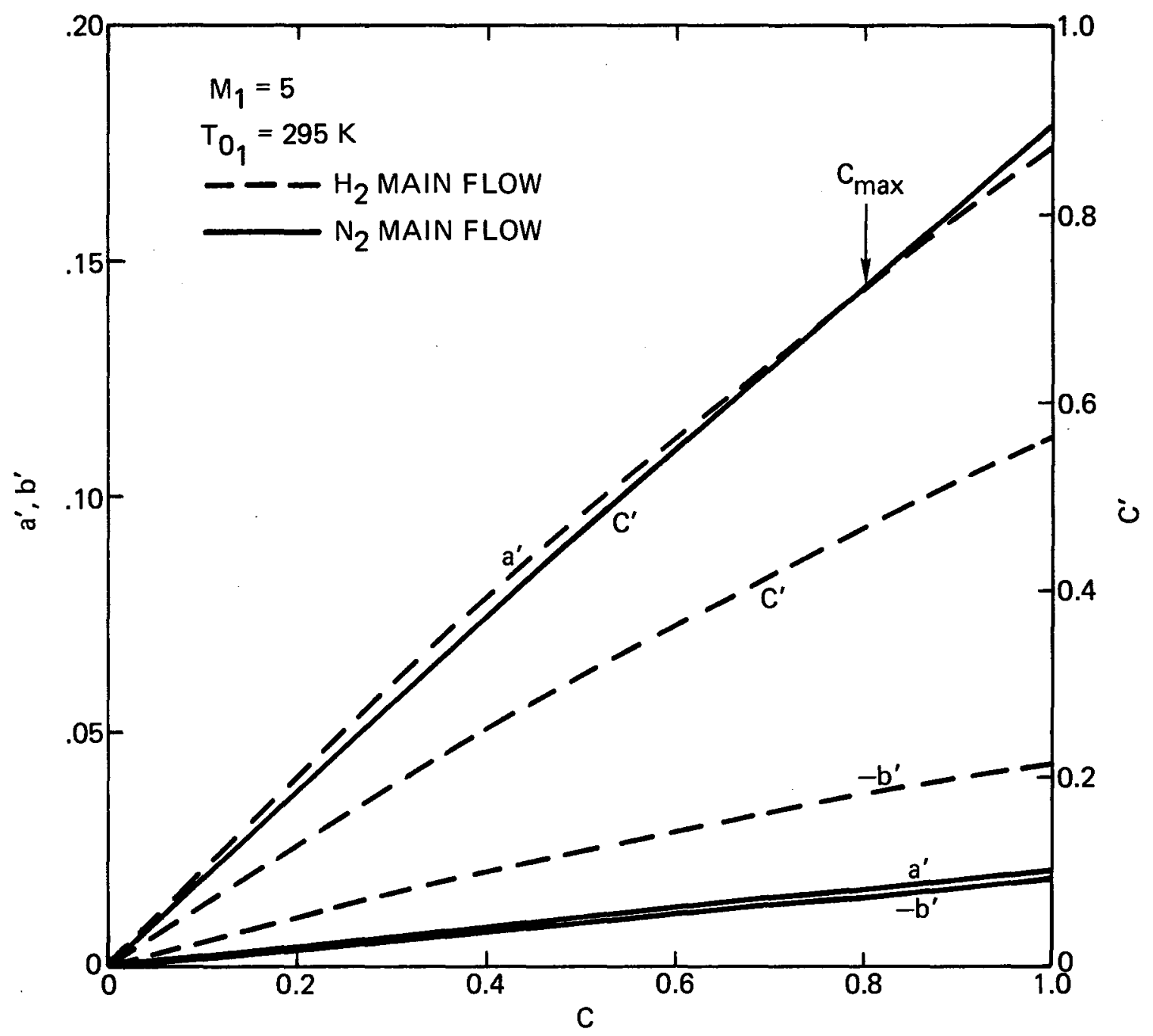

Figure 4: Dimensionless Mass, Momentum and Energy Addition by Combustion vs. Dimensionless Energy Addition by Ion Beam. Curves for $c>c_{\max }$ are Approximately Correct Since $a^{\prime}$ is a Weak Function of Mach Number for $\mathrm{M}_{1}>3.5$ 
nitrogen was used as the opposed jet gas and the main flow was composed of premixed combustible gases. This flow configuration seems more taxing on the critical zone (flame stabilization region) than the configuration proposed here since in the former, the secondary flow is entirely inert whereas in the one proposed here, the secondary flow is composed of combustible gases. It would seem that the flame is more likely to be stabilized if the secondary flow is composed of combustible gases because it is the secondary flow that predominately feeds the critical zone [5]. The problems likely to be encountered with a nitrogen main flow are not anticipated when hydrogen is used as the main flow. As a result, for safety reasons, the nitrogen main flow experiment will be attempted first and the hydrogen main flow experiment performed only if the nitrogen experiment fails to stabilize the flame.

In making the above and all subsequent calculations, the value of $\mathrm{q}$ was taken to be $3.21 \mathrm{kcal} / \mathrm{g}$. This is the heat of combustion of hydrogen at $25^{\circ} \mathrm{C}$. At temperature $\mathrm{T}$, $\mathrm{q}$ must be modified according to [18]

$$
\left.\mathrm{q}\right|_{\mathrm{T}}=\frac{1}{2 \hat{\mathrm{M}}_{\mathrm{g}}}\left[\Delta \mathrm{H}_{298}^{0}+\int_{298}^{\mathrm{T}}\left(2 \overline{\mathrm{C}}_{\mathrm{P}, \mathrm{H}_{2} \mathrm{O}}-\overline{\mathrm{C}}_{\mathrm{P}, \mathrm{O}_{2}}-2 \overline{\mathrm{C}}_{\mathrm{P}, \mathrm{H}_{2}}\right) \mathrm{dT}\right]
$$

for the reaction

$$
2 \mathrm{H}_{2}(\mathrm{~g})+\mathrm{O}_{2}(\mathrm{~g})=2 \mathrm{H}_{2} \mathrm{O}(\mathrm{g})
$$

where $\Delta \mathrm{H}_{298}^{0}$ is the enthalpy of formation at $298 \mathrm{~K}$ and $\overline{\mathrm{C}}_{\mathrm{P}}=\mathrm{A}+\mathrm{BT}+\mathrm{CT}^{2}$. The constants A, B and C are found empirically. 
The stagnation temperature of the combustible gases is about $25^{\circ} \mathrm{C}$. This gas mixture passes through a barrel shock wave [5] between exiting sonically from the secondary flow nozzle exit and entering the critical zone, where it again stagnates. If there were no turbulent diffusion of the burnt gases into the secondary stream, the secondary flow would thus arrive at the critical zone at its initial stagnation temperature. However, it is well known [6] that turbulent diffusion is an important factor in opposed-jet flame stabilization. Therefore, it is likely that secondary stream combustion will take place at temperatures well above $25^{\circ} \mathrm{C}$. To obtain an estimate of how $q$ changes with $T$, a value of $T=1500 \mathrm{~K}$ was picked and $\mathrm{q}_{1500 \mathrm{~K}}$ calculated from the above equation. The result was $\mathrm{qI}_{1500 \mathrm{~K}}=3.33$, which is a $3.5 \%$ increase over the value at $25^{\circ} \mathrm{C}$. In the absence of temperature measurements or a more detailed analysis of the chemical kinetics of opposed jet combustion, the results of the above calculation will be used to justify neglecting changes in the value of $q$ with temperature in the temperature ranges anticipated in the simulation experiment.

An obvious facet of Figure 4 is that with nitrogen as the main gas, about an order of magnitude reduction in the required combustible gas flow rate is possible. This occurs because of the order of magnitude lower value of $C_{P}$ for nitrogen than hydrogen. As a result, for the same main gas mass flow rate, an order of magnitude lower stagnation enthalpy flux results for the nitrogen flow, meaning that an order of magnitude less energy addition is required to the nitrogen than the hydrogen flow. This may be viewed as being a scaled-down experiment in terms of required energy addition. If flame stabilization is possible for the nitrogen experiment, both important experimental results and experience in such things as opposed-jet combustible 
gas ignition, experimental procedures, etc. will be obtained with the nitrogen experiment prior to performing the hydrogen experiment, if that turns out to be necessary.

Although the results of Figure 4 have been obtained for $M_{1}=5$, they are approximately the same for a1l upstream Mach numbers above $\mathrm{M}_{1} \cong 3.5$. The reason for this is that the momentum dissipation function $\tilde{G}$ is nearly constant with Mach number above $M_{1} \approx 3.5$ (Figure 5) and $a^{\prime}$ (i4) does not vary much as $M_{1}$ is increased above 3.5. This result agrees with the observations made earlier about (15) - i.e., the approximate form of $a^{\prime}$ is independent of $\mathrm{M}_{1}$. For example, for $\mathrm{M}_{1}=10, \mathrm{c}_{\max }=.972$ and $\mathrm{c}_{\max }^{\prime}$ is almost exactly predicted in Figure 4 for nitrogen and hydrogen main flows. In fact, there is less than a $4 \%$ error in these values for $M_{1}=\infty$ (i.e., $c=1$ ). For real solutions of $(8) \rightarrow(10)$ to exist, we require that

$$
1-\lambda \frac{2(\gamma+1) \mathrm{M}_{1}^{2}\left(1+\frac{\gamma-1}{2} \cdot \mathrm{M}_{1}^{2}\right)}{\left(1+\gamma \mathrm{M}_{1}^{2}\right)^{2}} \geq 0
$$

where the equality is used to obtain maximm conditions. For maximum conditions, there results

$$
\frac{(1+c)(1+a)}{(1+b)^{2}}=\frac{\left[\frac{\gamma_{2}}{\gamma_{1}}\left(\gamma_{1}+\frac{1}{M_{1}^{2}}\right)\right]^{2}}{\frac{2\left(\gamma_{2}{ }^{-1}\left(\gamma_{2}+1\right)\right.}{\left(\gamma_{1}{ }^{-1)}\right.}\left(\frac{1}{M_{1}^{2}}+\frac{\gamma_{1}^{-1}}{2}\right)}
$$

If we set $\gamma_{1}=\gamma_{2}=\gamma, a=b=0$, we arrive at the INS maximum energy addition of

$$
c_{\max }=\left(\frac{Q}{C_{P^{T}} T_{\text {max }}}\right)=\frac{\left(1-M_{1}^{2}\right)^{2}}{2(\gamma+1) M_{1}^{2}\left(1+\frac{\gamma-1}{2} M_{1}^{2}\right)}
$$




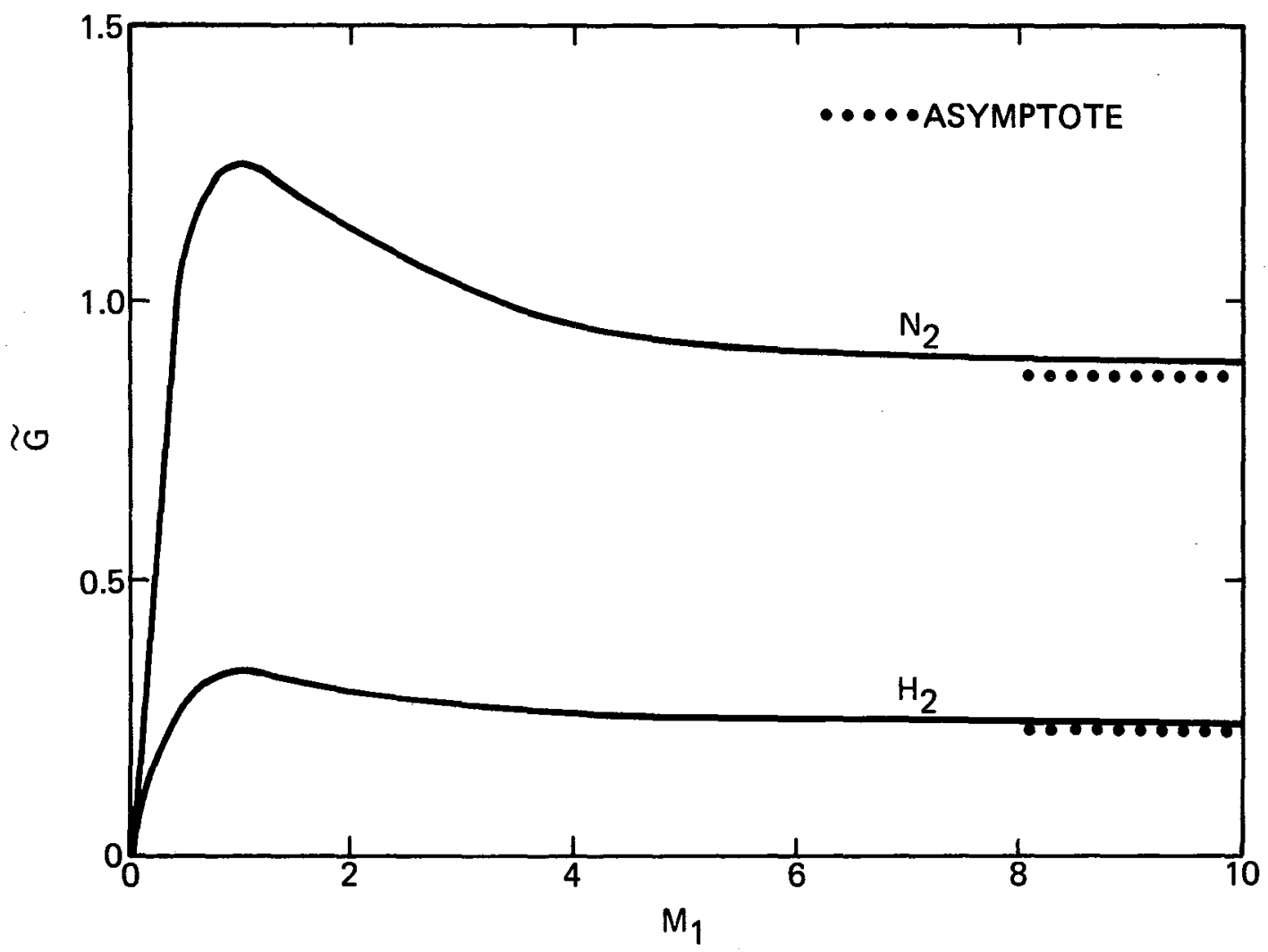

Figure 5: Momentum Dissipation Function vs. Upstream Mach Number 
If we look only at energy addition by combustion with $a^{\prime} \neq 0, b^{\prime} \neq 0$, $\gamma_{1}=\gamma_{2}=\gamma$ and $T_{0_{g}}=T_{0_{1}}$, we have

$$
\begin{aligned}
& a^{\prime}=c^{\prime} \frac{{ }_{\mathrm{P}_{1}}{ }^{\mathrm{T}} 0_{1}}{\mathrm{q}} \\
& \mathrm{b}^{\prime}=-\mathrm{c}^{\prime} \frac{{ }_{\mathrm{P}_{1}} \mathrm{~T}_{0}}{\mathrm{q}} \tilde{\mathrm{G}}
\end{aligned}
$$

for which we obtain the maximum energy addition for the simulation flow,

$$
c_{\max }^{\prime}=\omega\left\{\left(1-\frac{2(1-F)}{\omega}\left[\frac{{ }_{\mathrm{P}_{1}} \mathrm{~T}_{0}}{\mathrm{q}}(1+2 \tilde{\mathrm{GF}})+1\right]^{-1}\right)^{1 / 2}-1\right\}
$$

where

$$
\begin{gathered}
\omega=\frac{(1+2 \widetilde{G} F)+\frac{q}{C_{p_{1}{ }^{T} 0_{1}}}}{2\left(1-\widetilde{F G}^{2} \frac{\mathrm{C}_{1}{ }^{T}{ }_{1}}{q}\right)} \\
\left.F=\frac{\left(1+\gamma M_{1}^{2}\right)^{2}}{2 M_{1}^{2}(\gamma+1)\left(1+\frac{\gamma-1}{2} M_{1}^{2}\right.}\right)
\end{gathered}
$$

and

$$
\tilde{G}=\left[2 \frac{\hat{M}_{1}}{\hat{M}_{g}}(\gamma+1)\right]^{1 / 2} \frac{M_{1}\left(1+\frac{\gamma-1}{2} M_{1}^{2}\right)^{1 / 2}}{\left(1+\gamma M_{1}^{2}\right)}
$$


with

$$
\lim _{M_{1} \rightarrow \infty} \tilde{G}=\left(\frac{\hat{M}_{1}}{\hat{\mathrm{M}}_{g}}\right)^{1 / 2} \frac{\left(\gamma^{2}-1\right)^{1 / 2}}{\gamma}
$$

and

$$
\lim _{M_{1} \rightarrow \infty} F=\frac{\gamma^{2}}{\gamma^{2}-1}
$$

Equations (16) and (17) are plotted in Figure 6 for the INS flow (16) and for the simulation flow (17) having both a $\mathrm{H}_{2}$ and a $\mathrm{N}_{2}$ main flow. The top curve, $\left(\mathrm{Q} / \mathrm{C}_{\mathrm{P}} \mathrm{T}_{0}\right)_{\max }$ vs $\mathrm{M}_{1}$ can be found in [17] and reflects what occurs when only energy is added to the flow. As the initial Mach number $M_{1}$ goes to ${ }^{\infty},\left(\mathrm{Q} / \mathrm{C}_{\mathrm{P}} \mathrm{T}_{0}\right)_{\max } \rightarrow 1$. At this limit, all of the stagnation enthalpy has been converted to kinetic energy and the full $\mathrm{C}_{\mathrm{P}} \mathrm{T}_{0}$ can be added to the flow. The middle and bottom curves reflect what occurs when mass and energy are added and momentum is extracted from the main flow. These curves differ due to the different specific heats at constant pressure $C_{P}$ between nitrogen and hydrogen. Since nitrogen has a value of $C_{p}$ that is an order of magnitude lower than hydrogen, less combustible gas addition is required (for a given q) because less energy addition is required to drive $c^{\prime}$ to its maximum value. For hydrogen, about an order of magnitude more combustible gas flow rate is required to reach $c_{\max }^{\prime}$, so that more dimensionless mass and momentum are added and extracted from the main flow, respectively. Maximum values of $a^{\prime}$ and $b^{\prime}$, corresponding to the maximum values of $c^{\prime}$ in Figure 6 are given in Figures 7 and 8. The crossover of $a_{\max }^{\prime \prime}$ and - $b_{\max }^{\prime}$ for nitrogen occurs at $M_{1} \cong 3.3$ because at this Mach number, $\tilde{G}$ drops below unity. For $\tilde{G}>1,-b_{\max }^{\prime}>a_{\max }^{\prime}$ since $b_{\max }^{\prime}=-a_{\max }^{\prime} \tilde{G}$. 


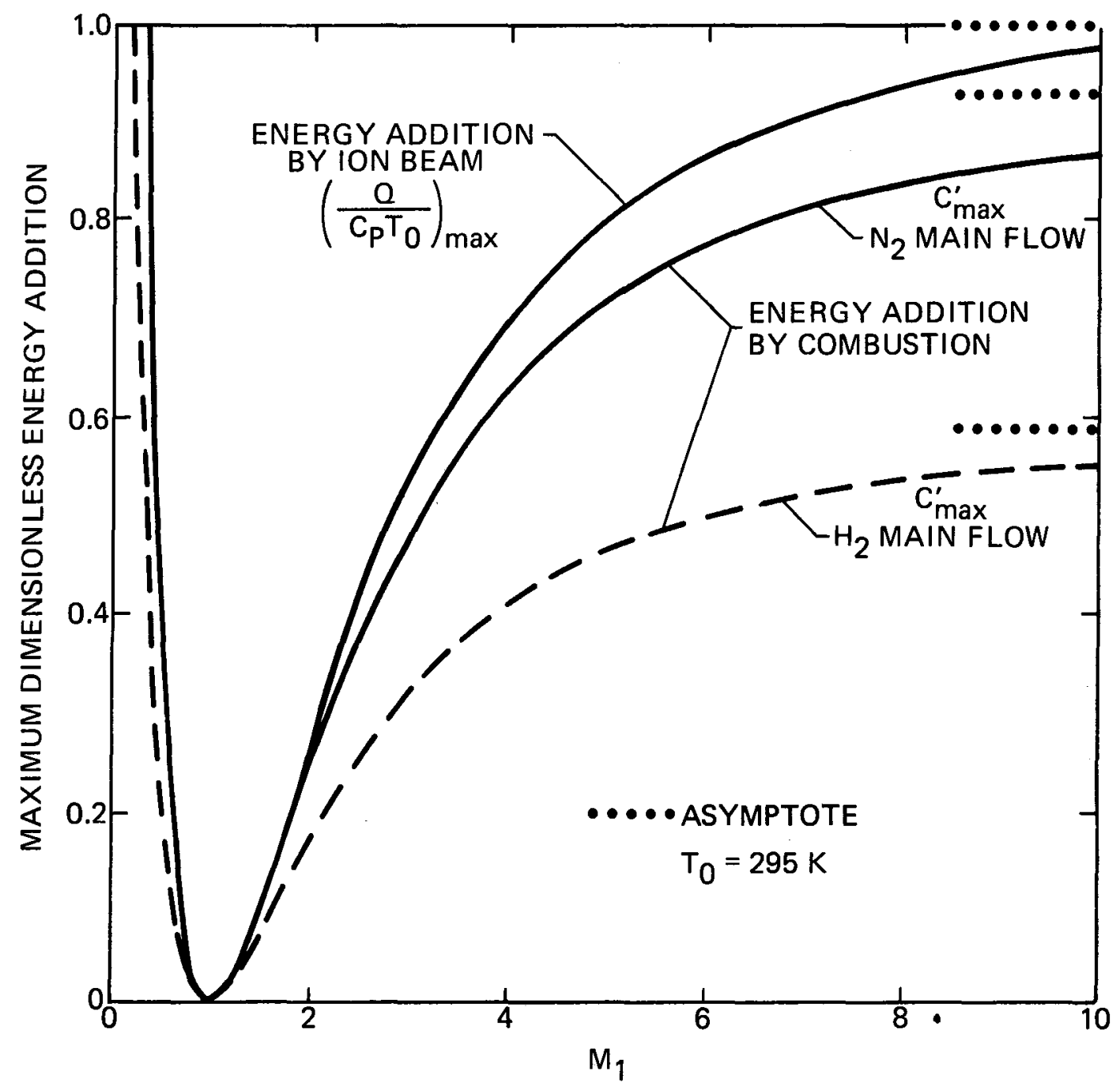

Figure 6: Maximu Dimensionless Energy Addition vs. Upstream Mach Number 


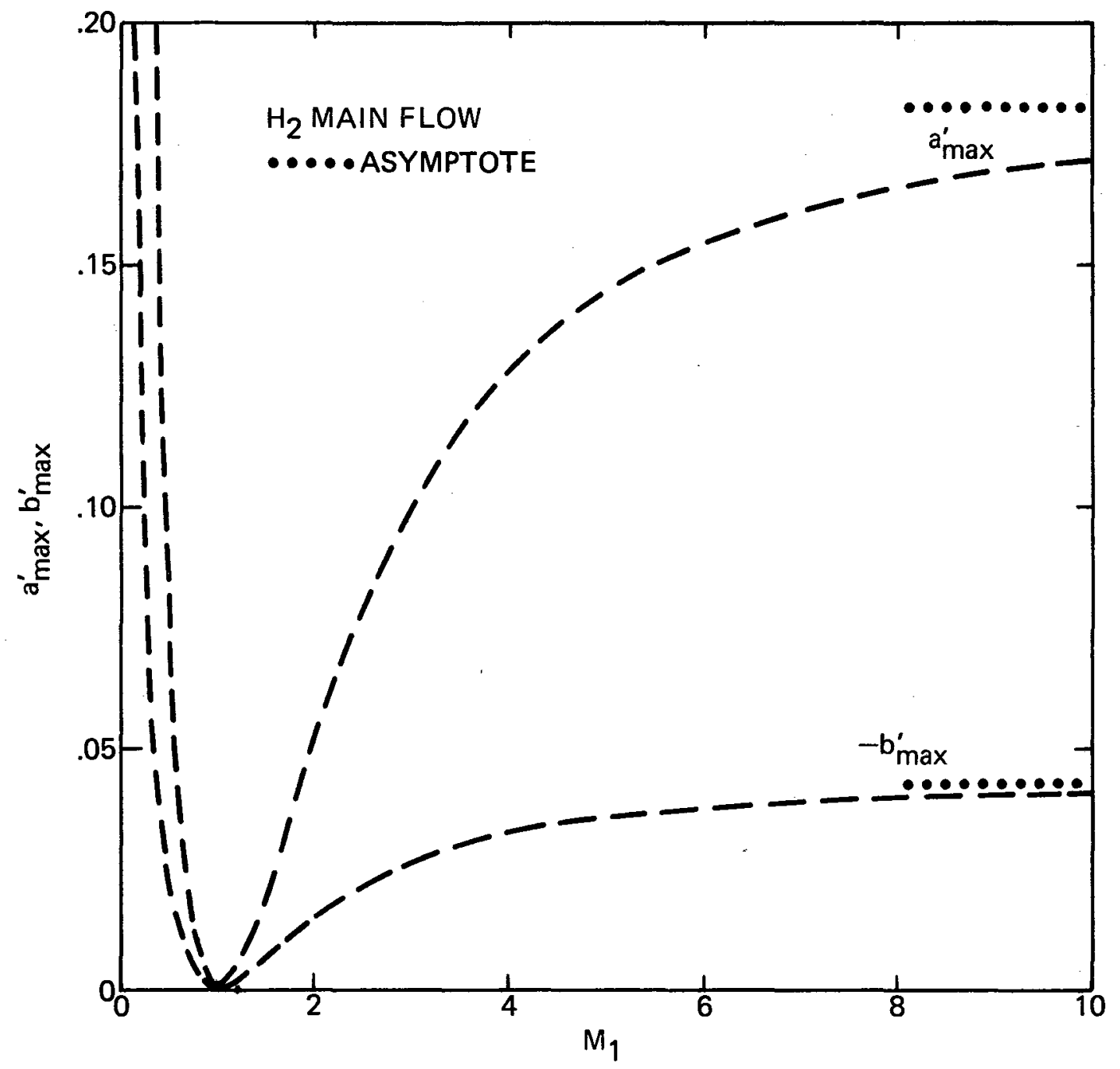

Figure 7: Maximum Dimensionless Mass and Momentum Addition vs. Upstream Mach Number.

Hydrogen Main Flow. 


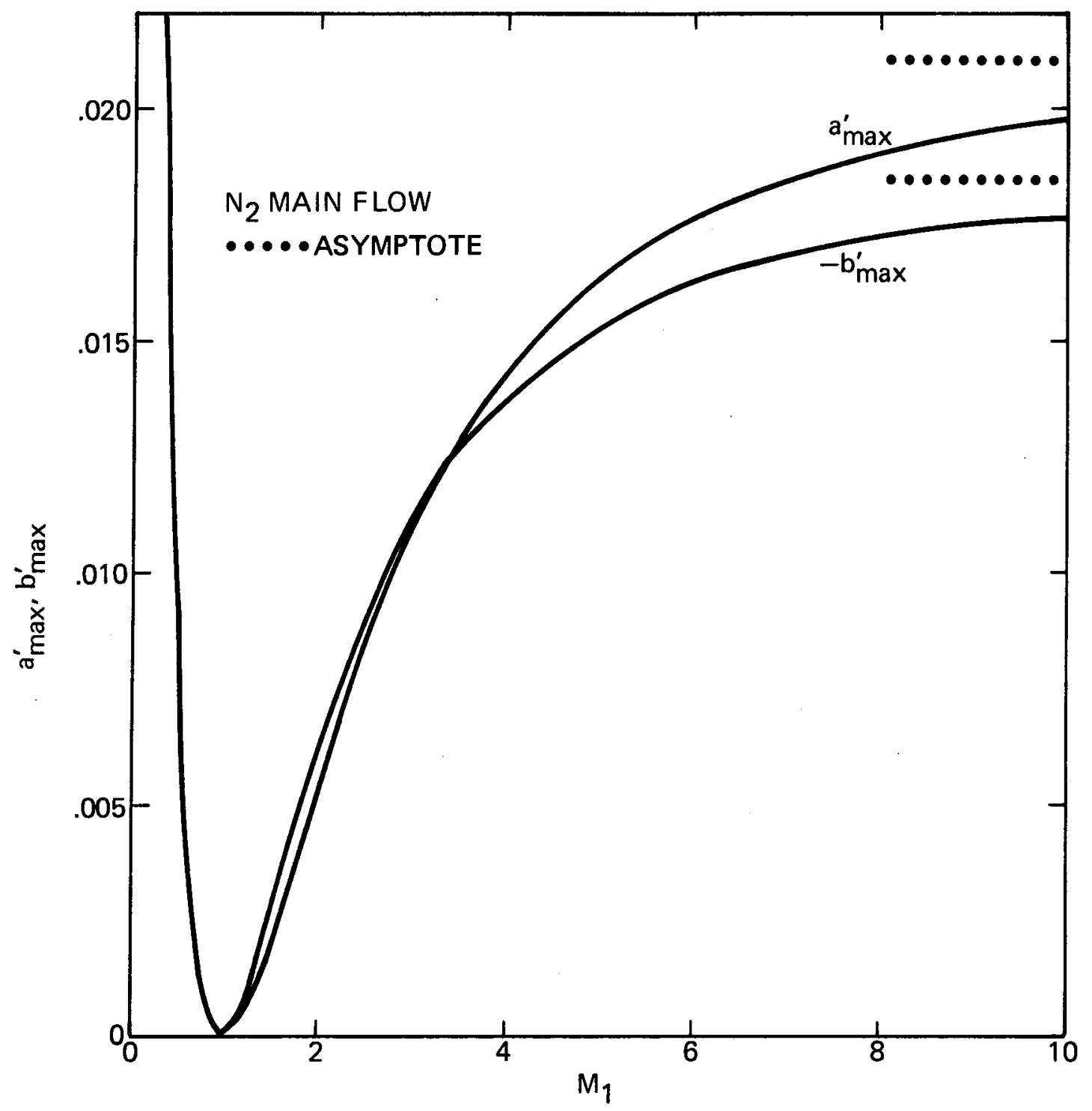

Figure 8: Maximum Dimensionless Mass and Momentum Addition vs. Upstream Mach Number.

Nitrogen Main Flow. 
The reduced flow quantities $(8) \rightarrow(10)$ describe how the INS and simulation flows differ when $\lambda^{\prime}$ 's are equal. For the INS flow, $a=b=\alpha=0$, $c \neq 0$. For the simulation flow $a^{\prime} \neq 0, b^{\prime} \neq 0, c^{\prime} \neq 0, \alpha \neq 0$. If it is assumed that both flows undergo the same transformation (e.g., normal shock), then

$$
\begin{gathered}
\frac{\left(\rho_{1} / \rho_{2}\right)}{\left(\rho_{1} / \rho_{2}\right)^{\prime}}=\frac{\left(1+a^{\prime}\right)^{2}}{(1-\alpha)\left(1+b^{\prime}\right)} \\
\frac{\left(V_{2} / V_{1}\right)}{\left(V_{2} / V_{1}\right)^{\prime}}=\frac{\left(1+a^{\prime}\right)}{\left(1+b^{\prime}\right)} \\
\frac{\left(P_{2} / P_{1}\right)}{\left(P_{2} / P_{1}\right)^{\prime}}=\frac{(1-\alpha)}{\left(1+b^{\prime}\right)} \\
\frac{M_{2}^{2}}{M^{\prime 2}}=1
\end{gathered}
$$

The most important parameters which should be duplicated between the simulation and INS flows are pressure and Mach number. Flow velocity and density are of secondary importance. However, since $\mathrm{M}_{2}=\mathrm{M}_{2}^{\prime}$, only the pressure ratio need be investigated. This is done in Figure 9 for four different values of $\alpha$. The greatest value of $\alpha$ to be used in the Sandia flow is less than .3 so that in the worst case less than a $30 \%$ difference between $\left(\mathrm{P}_{2} / \mathrm{P}_{1}\right)$ and $\left(\mathrm{P}_{2} / \mathrm{P}_{1}\right)^{\prime}$ can be expected. Since pressures become uniform much sooner down the channel than do either temperature or density, it is possible to experimenta1ly check the one-dimensional model by measuring $P_{2}$ and $P_{1}$ and using (9) to determine whether $P_{2} / P_{1}$ is given by 


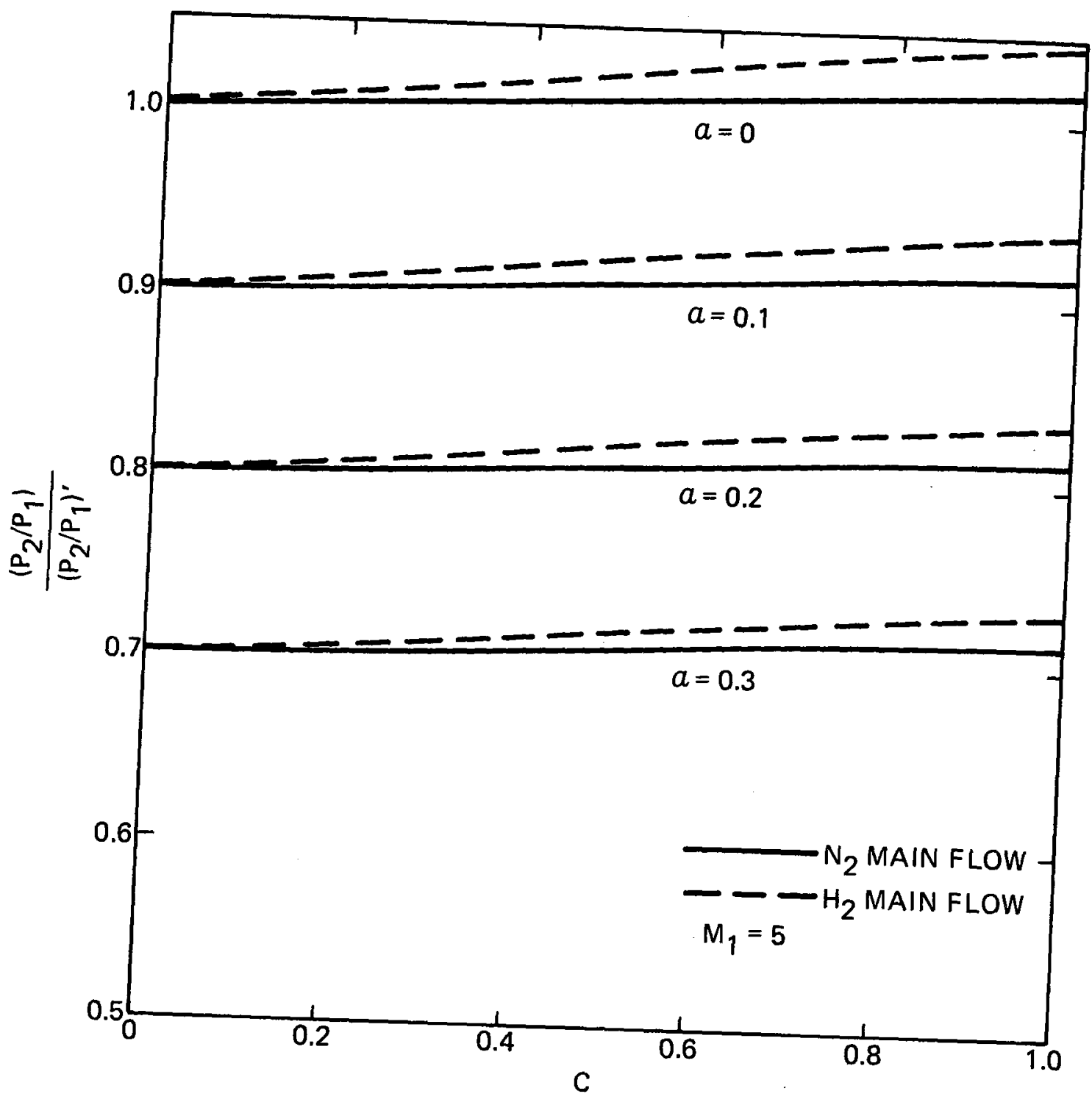

Figure 9: Pressure Ratio Variations 
$(1+b) G^{\prime}\left(\gamma, M_{1}^{2}, \lambda\right) /(1-\alpha)$. In making this calculation, $M_{1}$ can be determined optically by placing a wedge of known half-angle in the supersonic flow. A potential problem in checking out the analysis in this manner is that there may be oblique shock waves in the channel downstream of the step which make the location of station (2) for pressure measurement ambiguous. 


\section{Summary}

The work described herein was done to assess how realistically the Sandia experiment simulates the LASL INS experiment. In the INS experiment, a co-axial supersonic flow of deuterium provides both the gas target for a tritium ion beam and the means of dissipating the $1 / 3$ megawatt of heat which is deposited at the target by the $270 \mathrm{KeV}$ ion beam. Mass and momentum addition by the ion beam to the deuterium flow are negligible.

In the Sandia simulation experiment, energy is chemically deposited in a two-dimensional channel flow by an opposed-jet hydrogen-oxygen flame. An inherent consequence of this chemical energy deposition technique is that mass is added to and momentum is extracted from the main supersonic flow. Thus, the INS supersonic flow is perturbed only by energy addition while the simulation flow is perturbed by energy and mass addition as well as by momentum extraction.

To assess the effects of the differences between these two flows, a one-dimensional model of supersonic channel flow with mass, momentum and energy addition was developed. The governing conservation equations were written in terms of dimensionless mass, momentum and energy addition as we11 as for a step change in channel cross-sectional area. An exact solution to the governing equations was found and from this solution a similarity parameter identified. The similarity parameter relates dimensionless mass, momentum and energy addition. By equating this similarity parameter between two flows having different dimensionless mass, momentum and energy addition (or subtraction), an equality between the flows in terms of reduced flow quantities (flow parameters modified by ratios of the dimensionless additions) 
results. Application of this technique to the INS and simulation flows led to an expression relating dimensionless mass addition in the simulation experiment to dimensionless energy addition in the INS experiment. With this result, it is possible to calculate what mass flow rate of $\mathrm{H}_{2}-\mathrm{O}_{2}$ is required to simulate energy addition in the INS flow taking into account the fact that the combustible gases add mass and extract momentum from the simulation flow but that negligible mass and momentum are added in the INS flow. This calculation turned out to be approximately correct for all Mach numbers above about 3.5 .

Another aspect of the simulation experiment which was identified as a result of this analysis has been that by using nitrogen rather than hydrogen for the main gas, a scaled-down simulation experiment results. This is due to the fact that less mass flow of combustible gas mixture is required to achieve the same proportion of energy addition to the main flow stagnation enthalpy because the value of the specific heat at constant pressure is an order of magnitude lower for nitrogen than for hydrogen. With nitrogen rather than hydrogen as the main flow and an order of magnitude less mass flow of combustible gases, a safer simulation experiment results. The most important parameters which should be duplicated between the simulation and INS flows are pressure and Mach number. Results of this analysis show that within the limitations of the one-dimensional model, downstream Mach numbers will be equal between the two flows. A worst-case estimate shows that less than a $30 \%$ difference between downstream to upstream static pressure ratios exist between the INS and simulation flows. From these results, it is believed that the Sandia flow can realistically simulate the INS flow. 
Appendix A - Derivation of 1-D Conservation Equations

If viscous effects are neglected, the center streamline of Fig. 2 can be replaced by a solid boundary and a half-span channel flow analysis made (Fig. 3). The channel flow is assumed to be one-dimensional at stations (1), (g) and (2) of the control surface shown in Fig. 3. Inside the control surface, the flow is two-dimensional. All thermodynamic processes are assumed to take place with an ideal gas. At sitation(2), the flows are assumed to be perfectly mixed and have a uniform temperature, pressure, density and velocity.

Conservation of Mass

$$
\dot{\mathrm{m}}_{2}=\dot{\mathrm{m}}_{1}+\dot{\mathrm{m}}_{\mathrm{g}}
$$

or, in terms of dimensionless mass addition, a,

$$
\dot{\mathrm{m}}_{2}=\dot{\mathrm{m}}_{1}(1+\mathrm{a})
$$

where $\mathrm{a} \equiv \dot{\mathrm{m}}_{\mathrm{g}} / \dot{\mathrm{m}}_{1}$

For one-dimensional flow, (A-1) becomes

$$
\rho_{2} V_{2} A_{2}=\rho_{1} V_{1} A_{1}(1+a)
$$


Since the flow is in a two-dimensional channel, the areas may be written

$$
A_{1}=L H, A_{2}=L(H-h), A_{g}=L h^{\prime}
$$

where $L$ is the width of the channe1 and $h^{\prime} \leq h . \quad(A-2)$ reduces to

$$
\rho_{2} V_{2}=\rho_{1} V_{1} \frac{(1+a)}{(1-\alpha)}
$$

where $\alpha \equiv \mathrm{h} / \mathrm{H}$; and represents dimensionless step height.

\section{Conservation of Momentum}

In terms of stream forces and momentum fluxes at the entrance and exit of the control surface, the momentum equation is

$$
\mathrm{P}_{1} \mathrm{~A}_{1}+\dot{\mathrm{m}}_{1} \mathrm{~V}_{1}-\left(\mathrm{P}_{\mathrm{g}} \mathrm{A}_{\mathrm{g}}+\dot{\mathrm{m}}_{\mathrm{g}} \mathrm{V}_{\mathrm{g}}\right)=\mathrm{P}_{2} \mathrm{~A}_{2}+\dot{\mathrm{m}}_{2} \mathrm{~V}_{2}
$$

The term $\mathrm{P}_{\mathrm{g}} \mathrm{A}_{\mathrm{g}}+\dot{\mathrm{m}}_{\mathrm{g}} \mathrm{V}_{\mathrm{g}}$ may be thought of as a resultant force acting on the flow inside the control volume and arises from secondary flow impingement on the main flow. At station (2), the main and secondary flows are assumed to be perfectly mixed with the velocity $\mathrm{V}_{2}$.

This equation reduces to

$$
P_{2}+\rho_{2} V_{2}^{2}=\left(P_{1}+\rho_{1} V_{1}^{2}\right) \frac{(1+b)}{(1-\alpha)}
$$

where

$$
b=-\alpha^{\prime} \frac{P_{g}}{P_{1}} \frac{\left(1+\gamma_{g} M_{g}^{2}\right)}{\left(1+\gamma_{1} M_{1}^{2}\right)}
$$


and

$$
\alpha^{\prime}=h^{\prime} / \mathrm{H}
$$

The term $b$ is the dimensionless momentum addition and is negative since momentum is being extracted from the main flow. Since the secondary flow is composed of premixed combustible gases, it is desirable to have $\mathrm{M}_{\mathrm{g}}$ as large as possible to aid in preventing flashback up the secondary flow nozzle. In addition, secondary jet penetration (at sonic velocity) into the main stream is greater as $\mathrm{P}_{\mathrm{g}}$ is increased $[5,6]$. These two requirements indicate that the secondary flow should enter the control volume sonically (which is the maximm possible for a constant area secondary duct). For sonic secondary flow at station (g), (A-5) becomes, in terms of dimensionless mass addition a,

$$
\mathrm{b}=-\mathrm{a} \frac{\mathrm{h}_{1}^{*}}{\mathrm{H}}\left[2 \frac{\gamma_{1}}{\gamma_{\mathrm{g}}} \frac{\mathrm{T}_{\mathrm{g}}}{\mathrm{T}_{0}} \frac{\hat{\mathrm{M}}_{1}}{\hat{\mathrm{M}}_{\mathrm{g}}}\left(\gamma_{\mathrm{g}}+1\right)\left(\frac{2}{\gamma_{1}+1}\right)^{\frac{\gamma_{1}+1}{\gamma_{1}-1}}\right]^{1 / 2} \frac{{ }_{0_{1}}}{\mathrm{P}_{1}} \frac{1}{1+\gamma_{1} \mathrm{M}_{1}^{2}}
$$

where $\hat{M}_{1}$ and $\hat{M}_{g}$ are the molecular weights of the primary and secondary flow gases, respectively, and $h_{i}^{*}$ is the primary flow throat height.

Schlieren photographs [19] of the channe1 flow show that the main flow passes through an oblique shock wave before reaching station(1). If total pressure loss through the oblique shock wave is neglected, $\mathrm{P}_{0_{1}} / \mathrm{P}_{1}$ and $\mathrm{h}_{1}^{*} / \mathrm{H}$ can be expressed in terms of main stream Mach number at station (1), i.e.,

$$
\begin{gathered}
\frac{{ }_{0_{1}}}{\mathrm{P}_{1}}=\left(1+\frac{\gamma_{1}-1}{2} \mathrm{M}_{1}^{2}\right)^{\frac{\gamma_{1}}{\gamma_{1}^{-1}}} \\
\frac{\mathrm{h}_{1}^{*}}{\mathrm{H}}=\mathrm{M}_{1}\left[\left(\frac{2}{\gamma_{1}+1}\right)\left(1+\frac{\gamma_{1}-1}{2} \mathrm{M}_{1}^{2}\right)\right]^{\frac{\gamma_{1}+1}{2\left(1-\gamma_{1}\right)}}
\end{gathered}
$$


and (A-6) becomes

$$
b=-a \tilde{G}
$$

where

$$
\tilde{G}=\left[2 \frac{\gamma_{1}}{\gamma_{g}} \frac{\mathrm{T}_{0}}{\mathrm{~T}_{0}} \frac{\hat{\mathrm{M}}_{1}}{\hat{\mathrm{M}}_{\mathrm{g}}}\left(\gamma_{\mathrm{g}}+1\right)\right]^{1 / 2} \frac{\mathrm{M}_{1}\left(1+\frac{\gamma_{1}-1}{2} \mathrm{M}_{1}^{2}\right)^{1 / 2}}{\left(1+\gamma_{1} \mathrm{M}_{1}^{2}\right)}
$$

\section{Conservation of Energy}

The channel flow within the control volume is assumed to consist of three flows:

- a nonreacting main flow,

a secondary flow of perfectly mixed gases containing

- a chemically reacting component

- a nonreacting carrier-gas component

The purpose of the carrier-gas component is to provide the flexibility of altering the secondary mass flow rate and exit pressure without altering the energy deposition to the main flow.

The energy equation for the control volume is

$$
\left(\dot{\mathrm{m}}_{1}+\dot{\mathrm{m}}_{\mathrm{g}}\right)\left(\mathrm{h}_{2}+\frac{\mathrm{V}_{2}^{2}}{2}\right)-\dot{\mathrm{m}}_{1}\left(\mathrm{~h}_{1}+\frac{\mathrm{V}_{1}^{2}}{2}\right)-\dot{\mathrm{m}}_{\mathrm{g}}\left(\mathrm{h}_{\mathrm{g}}+\frac{\mathrm{V}_{\mathrm{g}}^{2}}{2}\right)=\left(\dot{\mathrm{m}}_{1}+\dot{\mathrm{m}}_{\mathrm{g}}\right) \mathrm{Q}
$$

where $Q$ is energy addition to the flow per unit mass by any means other than secondary stream combustion and includes conduction, radiation or energy addition through plasma (ion beam) interaction. 
The enthalpy change part of (A-9) can be written as

$$
\left(\dot{\mathrm{m}}_{1}+\dot{\mathrm{m}}_{\mathrm{g}}\right) \mathrm{h}_{2}-\left(\dot{\mathrm{m}}_{1} \mathrm{~h}_{1}+\dot{\mathrm{m}}_{\mathrm{g}} \mathrm{h}_{\mathrm{g}}\right)=-\mathrm{q} \dot{\mathrm{m}}_{\mathrm{r}}+\dot{\mathrm{m}}_{\mathrm{g}} \mathrm{C}_{\mathrm{P}_{\mathrm{g}}}\left(\mathrm{T}_{2}-\mathrm{T}_{\mathrm{g}}\right)+\dot{\mathrm{m}}_{1} \mathrm{C}_{\mathrm{P}_{1}}\left(\mathrm{~T}_{2}-\mathrm{T}_{1}\right)
$$

where

$$
\mathrm{C}_{\mathrm{P}_{\mathrm{g}}^{*}} \equiv \frac{\dot{\mathrm{m}}_{\mathrm{r}}}{\dot{\mathrm{m}}_{\mathrm{g}}} \mathrm{C}_{\mathrm{P}_{\mathrm{r}}}+\frac{\dot{\mathrm{m}}_{\dot{i}}}{\dot{\mathrm{m}}_{\mathrm{g}}} \mathrm{C}_{\mathrm{P}_{\dot{i}}}
$$

and

$$
\dot{\mathrm{m}}_{\mathrm{g}}=\dot{\mathrm{m}}_{\mathrm{r}}+\dot{\mathrm{m}}_{\mathrm{i}}
$$

$\dot{\mathrm{m}}_{\mathrm{r}}$ and $\dot{\mathrm{m}}_{\mathrm{i}}$ are the mass flow rates of the reacting and inert components of the secondary flow, respectively. $\mathrm{C}_{\mathrm{p}_{\mathrm{g}}}$ is an average specific heat at constant pressure for the secondary flow weighted by the respective mass flow rates of the secondary flow.

In writing (A-10), the secondary flow enthalpy change is treated [21] as being composed of a heat release per unit mass $q$ and a thermal energy change of both secondary flow components of $\mathrm{C}_{\mathrm{P}_{\mathrm{g}}}\left(\mathrm{T}_{2}-\mathrm{T}_{\mathrm{g}}\right)$. Main flow enthalpy change is comprised only of the thermal energy change $C_{P_{1}}\left(T_{2}-T_{1}\right)$. The flows are assumed to be perfectly mixed thermally at station (2), having an average specific heat at constant pressure of

$$
\mathrm{C}_{\mathrm{P}_{2}}=\frac{1}{1+\mathrm{a}} \mathrm{C}_{\mathrm{P}_{1}}+\frac{\mathrm{a}}{1+\mathrm{a}} \mathrm{C}_{\mathrm{P}_{\mathrm{g}}}
$$

where

$$
\mathrm{C}_{\mathrm{P}_{1}} \neq \mathrm{C}_{\mathrm{P}_{1}}(\mathrm{~T}) \text { and } \mathrm{C}_{\mathrm{P}_{\mathrm{g}}} \neq \mathrm{C}_{\mathrm{P}_{\mathrm{g}}}(\mathrm{T})
$$


With (A-10) and (A-11), (A-9) becomes

$$
\frac{r_{2}}{\gamma_{2}-1} \frac{P_{2}}{\rho_{2}}+\frac{V_{2}^{2}}{2}=\left[\frac{r_{1}}{\gamma_{1}-1} \frac{P_{1}}{\rho_{1}}+\frac{V_{1}^{2}}{2}\right] \frac{(1+c)}{(1+a)}
$$

where the dimensionless energy addition $c$ is given by

$$
c=a \frac{\left({ }_{P_{g}} T_{0}+q\right)}{C_{P_{1}} T_{0}}-\hat{a} \frac{q}{C_{P_{1}} T_{0}}+(1+a) \frac{Q}{C_{P_{1}}{ }^{T_{0}}}
$$

and

$$
\hat{\mathrm{a}}=\frac{\dot{\mathrm{m}}_{\mathrm{i}}}{\dot{\mathrm{m}}_{\mathrm{j}}}, \quad \tilde{\mathrm{a}}=\frac{\dot{\mathrm{m}}_{\mathrm{r}}}{\dot{\mathrm{m}}_{1}}
$$

The dimensionless mass additions are related by

$$
a=\tilde{a}+\hat{a}
$$

where

$$
\begin{array}{ll} 
& \tilde{a} \rightarrow 0 \\
\text { and } & \hat{a} \rightarrow 0 \\
\text { as } & a \rightarrow 0
\end{array}
$$

When no carrier gas is used, $\hat{a} \rightarrow 0$ and $(A-13)$ becomes

$$
c=a \frac{\left({ }_{P_{g}} T_{0}+q\right)}{C_{P_{1}}{ }^{T}{ }_{1}}+(1+a) \frac{Q}{C_{P_{1}} T_{0_{1}}}
$$




\section{Appendix B - Effects of a Carrier Gas in Secondary Stream}

An inert carrier gas is used in the secondary gas flow to change the secondary flow stagnation pressure and thus mass flow rate without changing the combustible gas mass flow rate (and hence chemical energy deposition rate). By again equating $\lambda^{\prime} s$ between the simulation and INS flows and applying conservation of mass to the secondary flow,

$$
a^{\prime}=\tilde{a}^{\prime}+\hat{a}^{\prime}
$$

there results

$$
\begin{aligned}
\tilde{a}^{\prime}=\Phi\left\{\left[1-\frac{2}{\Phi}\left[2(1+c) \hat{a}^{\prime} \tilde{G}-c\right]\left[1+\frac{q}{C_{P_{1}{ }^{T} 0_{1}}}+2(1+c) \tilde{G}\right.\right.\right. \\
\left.\left.\left.+\hat{a}^{\prime}\left(\frac{q}{C_{P_{1}}{ }^{T} 0_{1}}-2[1+c] \tilde{G}^{2}\right)\right]^{-1}\right]^{1 / 2}-1\right\}
\end{aligned}
$$

where

$$
\Phi=\frac{\left[1+\frac{q}{\mathrm{C}_{\mathrm{P}_{1}{ }^{\mathrm{T}} 0_{1}}}+2(1+c) \tilde{a}^{\prime}+\hat{a}^{\prime}\left(\frac{\mathrm{q}}{\mathrm{C}_{\mathrm{P}_{1}{ }^{\mathrm{T}} 0_{1}}}-2[1+c] \tilde{\mathrm{G}}\right)\right]}{2\left[\frac{\mathrm{q}}{\mathrm{C}_{\mathrm{P}_{1}{ }^{\mathrm{T}} 0_{1}}}-(1+\mathrm{c}) \tilde{\mathrm{G}}^{2}\right]}
$$


(B-1) has the approximate form

$$
\tilde{\mathrm{a}}^{\prime}=\frac{\mathrm{C}_{\mathrm{P}_{1}} \mathrm{~T}_{0_{1}}}{\mathrm{q}} \frac{\left[\mathrm{c}-2(1+\mathrm{c}) \hat{\mathrm{a}}^{\prime} \tilde{\mathrm{G}}\right]}{\tilde{\mathrm{a}}^{\prime}+1}\left\{1-\frac{\mathrm{C}_{\mathrm{P}_{1}} \mathrm{~T}_{0}}{\mathrm{q}} \frac{\left[\mathrm{c}-2(1+\mathrm{c}) \hat{\mathrm{a}}^{\prime} \tilde{\mathrm{G}}\right]}{\left(\hat{\mathrm{a}}^{\prime}+1\right)^{2}}\right\}
$$

For $\hat{a}^{\prime}=0$, this equation reduces to

$$
\tilde{a}^{\prime}=a^{\prime}=c \frac{\mathrm{C}_{\mathrm{P}_{1}} \mathrm{~T}_{0_{1}}}{\mathrm{q}}\left(1-c \frac{\mathrm{C}_{\mathrm{P}_{1}} \mathrm{~T}_{0_{1}}}{\mathrm{q}}\right)
$$

which is (15).

Dimensionless momentum and energy addition are, respectively,

$$
\begin{aligned}
& b^{\prime}=-a^{\prime} \tilde{G} \\
& c^{\prime}=\tilde{a}^{\prime} \frac{q}{C_{P_{1}}{ }^{T_{0}} 0_{1}}
\end{aligned}
$$




\section{REFERENCES}

[1] "Proceedings of the International Conference on Radiation Test Facilities for the CTR Surface and Materials Program," July 15-18, 1975, at Argonne National Laboratories.

[2] Emigh, C. R., Brolley, J. E. and Cline, M. C., "A Proposal for a 14-MeV Intense Neutron Source at Los Alamos, New Mexico," LA-5191-P, May, 1973.

[3] Lidsky, L. M., and Colombant, D., "High Intensity 14-MeV Neutron Source," IEEE Trans. Nuc1. Sci., NS-14, No. 3, 1967, p. 945.

[4] Robinson, J. E., Haasz, A. A., DeLeeuw, J. H., and Stangeby, P. C., "Electron Beam Heating of a Free Jet Gas Target," Nuclear Instruments and Methods, 121, 1974, pp. 287-296.

[5] Schaffer, A., "Phenomenological Analysis of the Opposing Jet Flameholder," PhD dissertation, Northwestern University, Evanston, Illinois, June, 1957.

[6] Choudhury, R., "The Effect of Tubulent Diffusion on Flame Stabilization," $\mathrm{PhD}$ dissertation, Northwestern University, Evanston, Illinois, August, 1958.

[7] Cambe1, A. B., "A Review of Flame Stabilization by Means of Gaseous Jets," Third AGARD Colloquim, Combustion and Propulsion, Pergamon Press, London, 541 (1958).

[8] Bohrer, L. C., "Some Performance Characteristics and Data Correlation for the Opposed Jet Flame Holder," M.S. thesis, Northwestern University, 1957. 
[9] Pohlmann, E., "Stabilizing Effects on an Opposing Jet of Air-Propane Mixtures in High Velocity Combustion," M.S. thesis, Northwestern University, 1954.

[10] Spalding, D. B., "Theory of Mixing and Chemical Reaction in Opposed Jet Diffusion Flames," ARS J, 31, 763, 1961.

[11] Bellamy, L., "A Critical Zone Analysis of Reverse Jet Flame Stabilization," PhD dissertation, Tulane University, 1966.

[12] Fluker, B. J., "An Investigation of the Effects of Unsteady Flow on Flame Stabilization by a Reverse Jet Flameholder," $\mathrm{PhD}$ dissertation, Tulane University, 1969.

[13] Strahle, W. C., "Theoretical Consideration of Combustion Effects on Base Pressure in Supersonic F1ight," Twelfth International Symposium on Combustion, The Combustion Institute, Pittsburgh, Penn., 1969, pp. $1163-1173$.

[14] Henry, J. R., "Recent Research on Fue1 Injection and Mixing and Piloted--Ignition for Scramjet Combustors," Twelfth International Symposium on Combustion, The Combustion Institute, Pittsburgh, Penn., 1969, pp. $1175-1182$.

[15] Tanner, M., "The Wake Pressure Behind Wedges as Influenced by Splitter Plates and Suction," AGARD, Separated Flows, Pt. 11, May, 1966, pp. 887-909.

[16] Billig, F. S., and Dugger, G. L., "The Interactions of Shock Waves and Heat Addition in the Design of Supersonic Combustors," Twelfth International Symposium on Combustion, The Combustion Institute, Pittsburgh, Penn., 1969, pp. 1125-1139.

[17] Zierep, J., "Theory of Flows in Compressible Media with Heat Addition," AGARDograph No. 191, May, 1974. 
[18] Daniels, F., and Alberty, R. A., Physical Chemistry, John Wiley and Sons, Inc., N.Y., 1966, pp. 58-61.

[19] Johnston, S. C., Unpublished experimental results.

[20] Williams, F. A., Combustion Theory, Addison-Wesley Publishing Company, Inc., 1965, p. 24. 
UNLIMITED DISTRIBUTION

INITIAL DISTRIBUTION :

Prof. Peter Stangeby

University of Toronto

Institute for Aerospace Studies

4925 Dufferin Street

Downsview, Ontario, CANADA, M3H5T6

Alan Forbes

38-135

Massachusetts Institute of Technology

Cambridge, MA 02139

J. A. Turi, ERDA

K. M. Zwilsky, ERDA

M. M. Cohen, ERDA

C. R. Emigh, LASL

M. C. Cline, LASL

K. Meier, LASL

J. C. Davis, LLL

M. Sparks, 1

W. J. Howard, 2

D. B. Shuster, 1300

R. C. Maydew, 1330; Attn: C. W. Peterson, 1334

J. C. Crawford, 2350

A. Narath, 5000

J. K. Galt, 5100

E. H. Beckner, 5200

R. A. Hill, 5262

K. J. Touryan, 5640

J. H. Scott, 5700; Attn: G. E. Brandvold, 5710

H. M. Stoller, 5730

T. B. Cook, Jr., 8000; Attn: C. H. DeSelm, 8200

W. C. Scrivner, 8400

L. Gutierrez, 8100; Attn: W. E. Alzheimer, 8120

D. E. Gregson, 8150

R. D. Cozine, 8160

A. N. Blackwel1, 8110

C. S. Selvage, 8180

A. F. Baker, 8111

D. L. Hartley, 8115

C. W. Robinson, 8116

K. R. Hencken, 8116

S. C. Johnston, 8116 (5)

B. F. Murphey, 8300

G. W. Anderson, 8330

W. Bauer, 8334

J. L. Wirth, 8340 
Technical Publications and Art Division, 8265, for TIC (2)

F. J. Cupps, 8265/Classification \& Technical Library Processing Div., 3141 Classification and Technical Library Processing Div., 3141 (4)

Library and Security Classification Div., 8266-2 